\title{
FRACTALS AS A METAPHOR IN DIALECTOLOGY
}

\author{
J. ROSENHOUSE 1,2 \\ ${ }^{1}$ SWANTECH Ltd., Israel. \\ ${ }^{2}$ Technion I.I.T., Israel.
}

\begin{abstract}
This article connects two science fields: one that belongs to the exact sciences (mainly mathematics), and the other-to linguistics, which belongs to the humanities. Linguistics is considered here as a phenomenon of nature. The main argument is that the way languages and dialects develop is similar to the behavior of random fractals in nature. Thus, the term 'fractals' and some of their features are compared to languages and their development. A basic organizing principle of fractals is self-similarity: fractals maintain their form regardless of the scale used. However, more details are revealed as the size scale changes and diminishes or grows. Fractals have a geometric shape that can be subdivided into parts, and each can be at least approximately a reduced-size copy of the whole. Such fluctuations are a kind of noise, which has been described as the essence of life, being random, uncertain and non-deterministic. The variety of noise spectra is defined by groups of features, specific signals and combinations of noise types. In languages, there are also basic structures, which develop into longer chains of utterances. These utterances can recur repetitively until some end, e.g. from speech sounds to words, and from them to phrases, sentences and whole texts. Another aspect of languages is that they have dialects. Their structures derive from a common core and acquire differences in time and space among dialects, in similar but variegated fashions. This comparison of fractals and languages/dialects reveals interesting similarities and differences. Examples are mainly taken from Arabic dialects.

Keywords: Arabic dialects, dialects, fractals, language.
\end{abstract}

\section{INTRODUCTION}

This article connects two different science fields: the exact sciences, expressed mainly in mathematics in the study of fractals, and linguistics, as part of humanities. The focus here is on the linguistic aspect. A short introduction on fractals, which is a popular and developing field of mathematics with many real-life natural applications, is given in the beginning. The linguistic aspect of this article will go into the development of dialects. The main argument is that the way languages and dialects develop bears similarity to the behavior of random fractals in nature. That is to say, language development is compared to some features of fractals.

\section{SOME FEATURES OF FRACTALS}

Here are some relevant notions related to fractals (cf. [1]):

- The organizing principle of fractals is self-similarity: fractals retain their original form regardless of the magnitude of the scale.

- More details are revealed or disguised as the size scale changes.

- It means that fractals have a geometric shape that can be subdivided into parts, each of which is at least approximately a reduced-size copy of the whole.

See the following snowflake and triangle shapes (Fig. 1). 

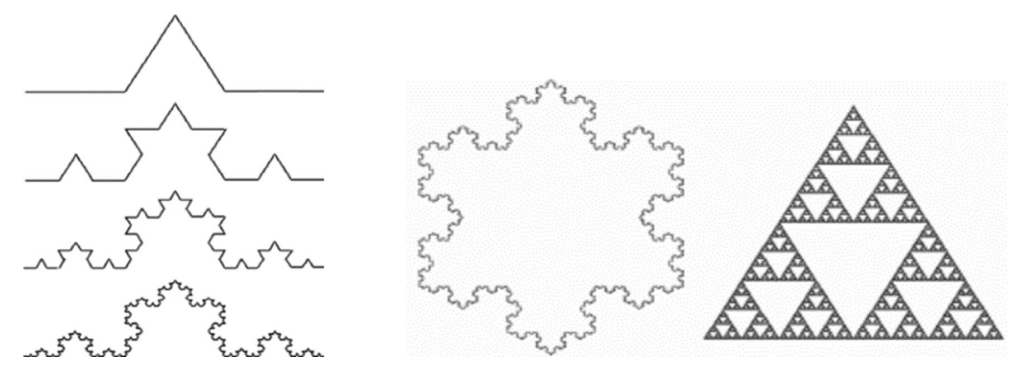

Figure 1: Some basic shapes of self-similar fractals (from: [2] http://www.fractalcurves.com/ Turtle.html)

In mathematics, self-similar fractals are accurate repetitions of the same form in different sizes, developed from formulas such as eqn (1).

$$
\mathrm{Z}=z^{2}+\mathrm{c}
$$

In real life, however, that is, in nature, forms have fractal-like features with statistical selfsimilarity, without mathematical accuracy. Therefore:

- Fractals can be complex and reflect the fluctuations that occur in nature.

- Fluctuations are a kind of noise.

- Noise is the essence of life as it is random, uncertain and non-deterministic. The variety of noise spectra is defined by groups, specific signals or noise type combinations [3].

See Fig. 2, which shows two natural forms $(\mathrm{a}, \mathrm{b})$ which are statistical fractals and an artificial (mathematical) fractal.

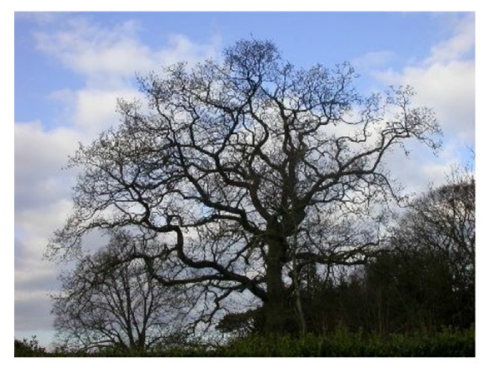

a

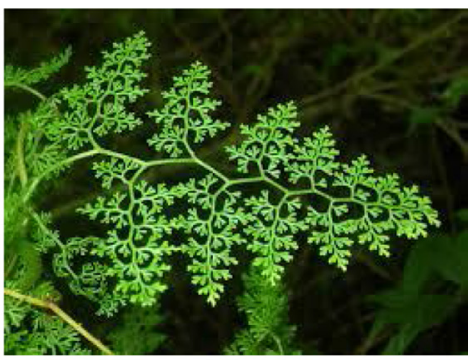

$\mathrm{b}$

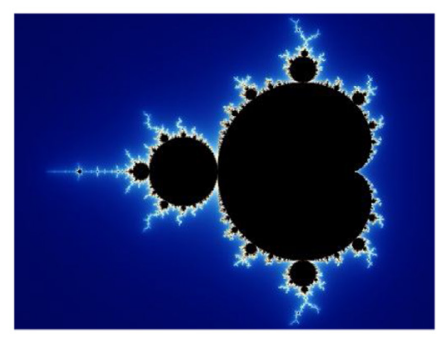

$\mathrm{c}$

Figure 2: Statistically random fractals in nature: a tree (a) from Jocaonstuff.com, and fern leaf (b), both from [4] and an artificial form, c from [5]. 


\section{LANGUAGES AND DIALECTS}

Language is the major human tool for communication and expression of speakers' thoughts, wishes, feelings, etc. (See e.g. [6]). How language began is a question, which we still cannot answer, as there are no traces of its emergence. Yet, people have been interested in this issue for millennia. The Tower of Babel story, described in the Hebrew Bible, tells about a huge construction project that failed due to linguistic, i.e. communication changes.

Modern linguistic research studies children's speech development from birth onward. [7] In addition to other goals, this area of research of their development stages can partly hint at how humans developed language. There is rich research on this aspect of linguistics, but it is still not clear to what extent it really reflects the history of human language development.

Comparative linguistics is a different linguistic field that deals with aspects of various languages of the same or different language families. These studies try to decode the common origin and the development routes of those languages.

These points come to note here the universality and fundamentality of languages and dialects and their developments. It has just been noted that various features of fractals are

everywhere in nature. The following discussion will touch on the similarity between fractals and languages based on some of the known facts about them.

The relatively firmer ground of modern dialects and some of their development routes in one century will now be discussed by comparing some of the phenomena that have fractal features.

Language structures include features of pronunciation, grammar and lexicon, all intertwined. However, languages are not homogenous, and some of the differences found in a language reflect language varieties, which are named dialects. Every normal human acquires a mother tongue (L1). Many also acquire another language (L2), usually later than L1. Many speakers may know more than two languages, and they use them according to their various needs and among the different speakers.

Many linguistic studies investigate dialects in different languages. But what are dialects? One definition is that dialects are language varieties that differ from other varieties at a considerable rate (see [8]). (Another humorous definition, attributed to the American linguist $U$. Weinreich, is that 'a dialect is a language without an army.') Dialects development, and some of their features as they appear in a specific language, are described below.

\section{THE DEVELOPMENT OF DIALECTS}

How do dialects develop? Here is the connection point of languages/dialects with nature, fluctuations and random fractals. It is assumed that in the past, groups of humans left their living center (perhaps in Africa) and moved to new areas. On the way, they split into smaller groups. These smaller groups settled down in various locations and began to develop their new life systems. Since in the past, moving from one place to another was difficult, once settled somewhere, moving elsewhere was scarce. Thus, the original, single speech manner (dialect or language) split into as many speech varieties as their new centers. This process continued for generations: The dialects that derived from the original language system, went on developing. Members of the new speech dialects may have moved away just as their ancestors had done, and in due course, their speech manner changed again, and new dialects (or sub-dialects) developed in the newly formed speech groups

Two models developed the theory of language [to dialect] development in the beginning of the twentieth century: the circular development and the tree development $[9,10]$. One model describes this process as beginning from a center and developing to all sides at equally 
growing circles (distances). Another model begins from an original spot and develops in time (with/without geographical distance) increasing the inter-dialect differences between the branches. These models do not explain, however, how these changes come by, how they physically begin in a speaker's mother tongue. Here, some fractal features, or rather, random fractals features are to be noted. Fractals, thus,

- look the same but may be presented in different scales of magnitude.

- The differences between fractals in the various scales are random and unpredictable.

- These forms fluctuate in groups, or specific signals and combinations (like noise in a sound system).

Language speakers differ in their physical features, including size, temperament, life histories, or education. These factors affect their speech features for they can imitate and learn other speakers' features and/or independently innovate features. These processes exist in all the linguistic domains and in linguistics they are named inter-speaker accommodation.

Phonetically, for example, a speaker (child or adult) learns how to pronounce words to sound like her/his mother, father, sibling, friend, teacher or others. This pronunciation may be like that of the L1 or an L2 used by the speakers in the community or from the outside. The learner may use the acquired form correctly or with some variation, which may result from impaired hearing, perception, or articulation. Studies have shown that pronunciation fluctuations of speech sounds (phonemes) occur even in a single speaker's speech when he repeats the same utterance a few times. That is why in many studies the same words are recorded more than once, and are then analyzed. The seminal paper by Peterson and Barney [11], for example, showed in their seminal paper differences between male and female adults' and children's vowels in American English.

Many other studies describe pronunciation differences in different dialects. The following figure 3 shows the differences between native Arabic-speaking men and women in two dialects in Israel [12] depicted in Formants ${ }^{1}$ of the short and long vowels of these dialects.

Here are some more examples of Arabic dialects. Many native speakers of Arabic live around the Mediterranean Sea in North Africa, Egypt, Israel, Jordan, Lebanon and Syria. Other Arabic dialects include Iraq, Saudi Arabia and countries further East in Asia and South in Africa. They speak the Arabic language, but use dialects that differ in various categories, while sharing features that grow from the fact, that, humans live in rather tightly knit social and cultural elements.

Figure 4 shows several Eastern Arabic dialects in the East Mediterranean area, starting with Egypt (painted in blue, orange and some cream colored areas. The latter reflect Bedouin dialects.). Further to the east and north we see Levant dialects of Israel, Jordan, Lebanon and Syria (painted in light green) and other dialect areas in the north and east of Syria (painted in

\footnotetext{
${ }^{1}$ A Formant $(\mathrm{F})$ is defined as the peak of the frequency spectrum of a sound that issues from the resonance frequencies of an acoustical system, including the human speech system. F1 (First Formant) reflects the tongue height in the vocal tract, while F2 (Second formant) reflects the locus of the tongue in the front or back of the vocal tract.

GD refers to the Galilee dialect, and MD refers to the Muthallath ('triangle') Dialects, both in Israel, which were studied in [12].
} 

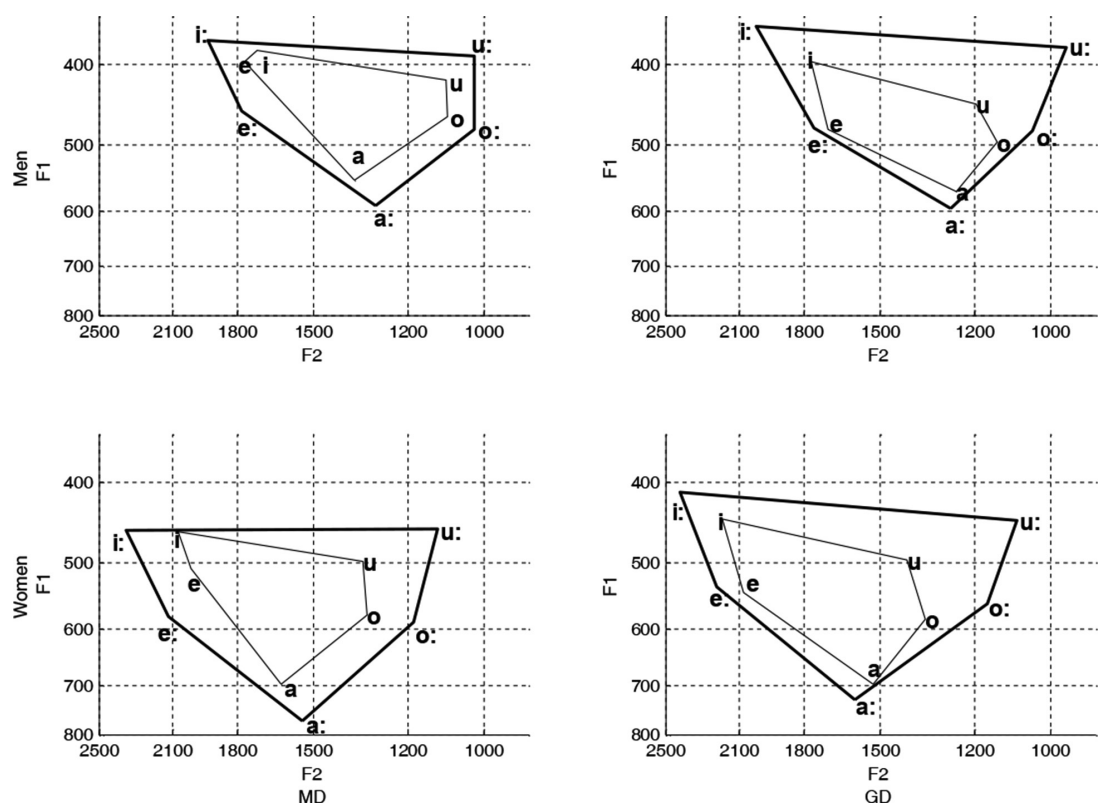

Figure 3: Vowel Formants in two Arabic dialects in Israel, the Triangle (MD) and Galilee (GD). The x-axis shows the first Formant (F1) and the y-axis shows the second Formant (F2). Each dialect has five vowel phonemes; the external trapeze mark the long vowels (/ii, ee, aa, oo, uu/). The inner trapezes mark the short vowels (/i, e, a, $\mathrm{o}, \mathrm{u} /$ ). The left column shows the Triangle Formants, and Galilee Formants are in the right column. Top rows are male results and bottom rows show the female results (cf. [12]).

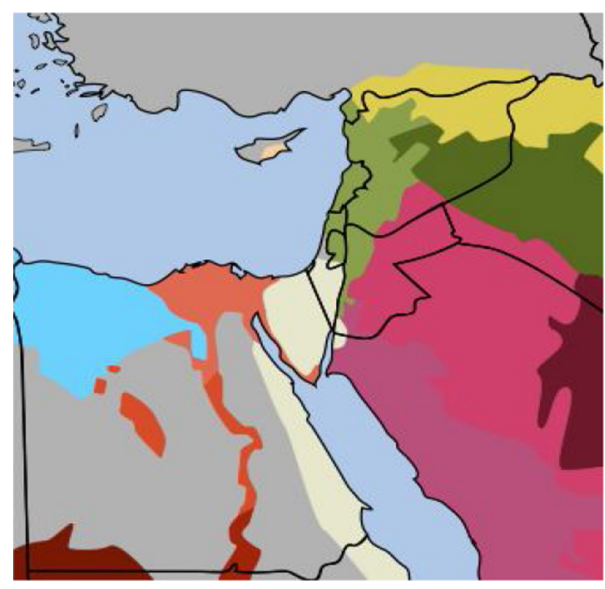

Figure 4: Map of Levant Arabic Dialects from [13]. https://learnammiyya.wordpress.com/ tag/sociolinguistics/ 
yellow and darker green), as well as Bedouin-type dialects in Eastern Jordan, Saudi Arabia and Iraq (painted in pink, purple and brown).

Generally, Arabic dialects (cf. [14]) are geographically split into:

- Eastern vs. Western dialects

Three demographic factors affect dialect features in the Arabic speaking countries:

- Urban (towns), rural (villages) and nomadic (Bedouin) dialects.

Other main dialect differences are based on:

- gender-male vs. female speech

- religion (faith), and

- education

Table 1 shows some examples of differences between Arabic dialects from nine Levant cities of four states in the Levant dialect region: Syria, Lebanon, Israel, Jordan and the Palestinian Authority. These examples show that these dialects share many basic features while other features distinguish one country's dialect from another. The examples demonstrate features of pronunciation (phonology/ phonetics), word form (morphology) and vocabulary; that is to say, they relate almost to all the linguistic areas. The differences marked in bold in Table 1 are discussed here briefly. In general, it should be noted that certain forms are common to several towns in this region, but there are more differences between the northern (Syrian) dialects and the southern ones (Lebanon, Israel and Jordan) than among the southern towns. Moreover, differences do not occur systematically: certain features differ between the dialects more than other features do. Certain differences are minimal (e.g. a variant of a vowel) but distinctive, e.g. /a/ vs. /I/.

Table 1: Examples of urban Levant Arabic consonants and vowels (accessed 24.1.2016 to: https://en.wikipedia.org/wiki/Levantine_Arabic_phonology) [15] The examples are written in IPA fonts.

\begin{tabular}{|c|c|c|c|c|c|c|c|}
\hline City & $q$ & g & we & $\begin{array}{l}\text { 2nd m.pl. } \\
\text { suffix }\end{array}$ & they & them & I say \\
\hline Aleppo & $?$ & $d_{3}$ & 'nəћne & -kon & 'hənnen & -hon & ba' Pu:l \\
\hline Damascus & $?$ & 3 & 'nəћna & -kon & 'hənnen & -hon & bPu:l \\
\hline Beirut & $?$ & 3 & 'nıћna & $-k v n$ & 'hinne & $-\delta n$ & b?u:l \\
\hline Haifa & $?$ & 3 & 'Iћna & $-k v$ & 'hinne & -hen & ba'?u:l \\
\hline Jerusalem & $?$ & 3 & 'Iћna & -kom & 'homme & -hom & ba'Pu:l \\
\hline Hebron & $?$ & dz & 'iћna & $-k v$ & 'homme & -hom & ba'?u:l \\
\hline Gaza & $?$ & 3 & 'Iћna & $-\mathrm{kv}$ & 'homma & -hom & ba'Pu:l \\
\hline Amman & $\mathrm{g}$ & $d_{3}$ & 'Iћna & $-\mathrm{k} u \mathrm{~m}$ & 'homme & -hom & ba'gu:l \\
\hline Al-Karak & $\mathrm{g}$ & d3 & 'Iћna & $-k o m$ & 'hummo & -hom & ba'gu:l \\
\hline
\end{tabular}




\begin{tabular}{|c|c|c|c|c|}
\hline City & I write & He writes & now & notis not ... \\
\hline Aleppo & 'baktob & 'biktðb & 'halla? & $\mathbf{m} \boldsymbol{~}$ \\
\hline Damascus & 'bəkteb & 'bjəkteb & 'halla? & $\mathrm{m} v$ \\
\hline Beirut & 'brktob & 'bjıktob & 'halla? & mis \\
\hline Haifa & 'baktrb & 'bIktıb & 'ISSa & $\mathrm{mI} \int$ \\
\hline Jerusalem & 'baktub & 'biktub & ha-l-' ae:t & $\mathbf{m} \delta \boldsymbol{\jmath}$ \\
\hline Hebron & 'baktob & 'brktob & ha?'ae:tI & $\operatorname{mos}$ \\
\hline Gaza & 'baktøb & 'biktub & 'halla? & $\mathrm{mI} \int$ \\
\hline Amman & 'baktub & 'brktub & ha-s'sa: $Y$ & $\operatorname{mos}$ \\
\hline Al-Karak & 'baktub & 'brktub' & has'sa:G & $\mathbf{m} \boldsymbol{\sigma}(\boldsymbol{\delta})$ \\
\hline
\end{tabular}

As noted, there are other dialects in this area, e.g. the Bedouin dialects that differ from sedentary (urban) dialects. The next examples in Table (2) are from North Israeli Bedouins vs. urban dialects (Haifa) in the same area.

By the way, Haifa Arabic [17] includes three basic communal dialects: those of Moslems, Christians and Jews. These dialects have changed in time and are mixed now with dialects of other speakers who have settled in Haifa during the twentieth century. Not only in Haifa, but also all over the country, people's migrations within Israel (and in Arab countries) have changed the dialects. Thus, as in the ancient past, migration affects dialect developments.

In addition, however, cultural changes have brought about new vocabulary items, and older lexical items have become obsolete. A study of Arabic dialects in Israel [24] examined the passive knowledge (recognition) and active use (production) of 120 lexical items in each of three groups of native speakers of Arabic. Forty-six speakers participated in the study: two groups were natives of Haifa and Nazareth, and used the urban dialects of Haifa and Nazareth, and the rest used rural dialects of ex-villages in central Israel in the Triangle area and around Jerusalem. These villages have grown and changed in time, and now they are officially towns. Each participant was asked whether s/he recognized the word, and whether s/he used it. Statistical analysis found differences that reflected dialect-related differences in their use of the test vocabulary. The main results are presented in Tables from that study. The abbreviations in the Tables (Table 3-5, and Fig. 5) indicate the authors' names of the publications from which the lexical items were chosen: H [18] Havelova 2000; GK [17] Geva-Kleinberger, 2004; MK [19] Meron and Kabha 1993; SK [20] Schmidt and Kahle, 1918. These books were chosen to investigate the development of the vocabulary of currently living urban and rural speakers and compare with that of the old population from the beginning of the twentieth century. The main results are presented in the following Tables 3-5.

Table 2: Examples of pronunciation in Galilee Bedouin [16] and Haifa dialects [17].

\begin{tabular}{|c|c|c|c|c|c|}
\hline Dialect Gloss & I say & three & $\begin{array}{l}\text { your (f.sg.) } \\
\text { House }\end{array}$ & Mountain & sitting(he) \\
\hline $\begin{array}{l}\text { Galilee Bedouin } \\
\text { Haifa Urban }\end{array}$ & $\begin{array}{l}\text { Pagu:1 } \\
\text { ba?u:1 }\end{array}$ & $\begin{array}{l}\text { Oala: } \theta \text { a } \\
\text { tala:te }\end{array}$ & $\begin{array}{l}\text { da:rit } \\
\text { da:rek }\end{array}$ & $\begin{array}{l}\text { dzibal } \\
\text { zabal }\end{array}$ & $\begin{array}{l}\text { ga:Yed/dZa:Yed } \\
\text { Pa:S'id }\end{array}$ \\
\hline
\end{tabular}


Table 3: Number and percentage of positive answers by book (rates of 30 words x 46 participants $=1380$ maximum possible answers). The statistical analysis revealed significant differences between all of them.

\begin{tabular}{lllll}
\hline Book & Familiarity & \% & Usage & \% \\
\hline H & 1155 & $\mathbf{8 3 . 7}$ & 992 & $\mathbf{7 1 . 9}$ \\
GK & 1110 & $\mathbf{8 0 . 4}$ & 983 & $\mathbf{7 1 . 2}$ \\
MK & 894 & $\mathbf{6 5 . 5}$ & 663 & $\mathbf{4 8}$ \\
SK & 867 & $\mathbf{6 2 . 8}$ & 658 & $\mathbf{4 7 . 7}$ \\
Total & 4036 & $\mathbf{7 3 . 1}$ & 3296 & $\mathbf{5 9 . 7}$ \\
\hline
\end{tabular}

Table 4: Answer results for familiarity and usage by gender.

\begin{tabular}{lll}
\hline \multicolumn{1}{c}{ Gender } & Men & Women \\
Category & & \\
\hline Familiarity & $\mathbf{8 0 . 2 0 \%}$ & $\mathbf{7 4 . 5 0 \%}$ \\
Usage & $\mathbf{6 8 . 7 \%}$ & $\mathbf{5 8 . 1 0 \%}$ \\
\hline
\end{tabular}

Table 5: Answers results for familiarity and usage by dialect.

\begin{tabular}{llll}
\hline \multicolumn{1}{c}{ Dialect } & Galilee & Triangle & Jerusalem area \\
Category & & & \\
\hline Familiarity & $\mathbf{7 6 . 4 0 \%}$ & $\mathbf{7 3 . 6 0 \%}$ & $\mathbf{7 8 . 4 0}$ \\
Usage & $\mathbf{6 3 . 1 0 \%}$ & $\mathbf{5 7 . 1 0 \%}$ & $\mathbf{6 3 . 2 0}$ \\
\hline
\end{tabular}

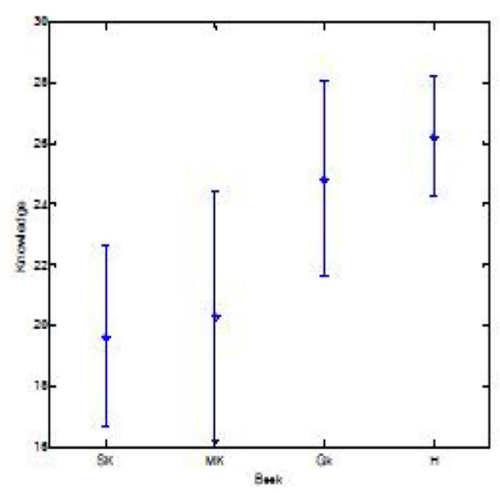

a

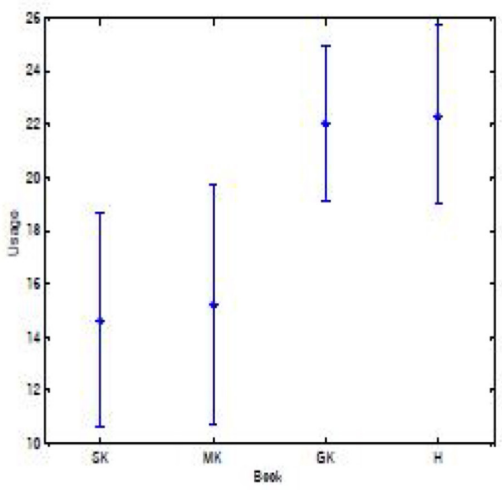

b

Figure 5: Results for Familiarity (a) and Usage (b) of words from the books. The paired T-test shows that for both Familiarity and Usage, the set of all SK and MK answers differs significantly from the answers of GK and $\mathrm{H}$. 
Table 3 shows that the statistical analysis revealed significant differences between all of the vocabulary lists in both the familiarity and usage of these words by the participants.

Table 4 shows differences between men's and women's familiarity with the vocabulary lists and their usage. The men were more familiar with the lexical items and used them more than the women did.

Table 5 shows differences in the familiarity and usage of the lexical lists between the three dialects. For familiarity, the urban dialects of Jerusalem area and Galilee scored higher than the rural Triangle dialect. A similar picture is seen concerning usage of the lexical items.

Figure 5 shows the results of familiarity and usage of the word lists from the four books. The differences are significant between the most recent word lists of urban dialects, with higher scores and smaller variance, and the older word lists from the dialects in the center of the country. These dialects mainly reflect rural and central regions with lower scores, and larger variance. (For discussion of details, see [24].)

In sum, this study reveals familiarity and usage differences due to the factors of location, gender and age, which characterize different dialects, concerning words from different periods in the twentieth century.And all this is just in Israel which is a small country.

\section{DISCUSSION AND CONCLUSIONS}

This article discussed examples of inter-dialect differences, using Arabic as the medium language. Similar phenomena are found between English dialects in many countries: British vs. American-, Indian-, South African, or Australian English. Dialect differences are found also within each of the English-speaking countries such as Great Britain, with its northern, central, $\mathrm{RP}^{2}$, London dialects, etc., the USA, with their northern, southern, central dialects and so on. Differences can be found also between female and male speech within each of these dialects. For example, Labov [22] did massive work on dialect changes in North American English and Trudgil [23] worked on different social dialects in northern England, etc. When looking at the languages around the Mediterranean Sea, we find dialects in e.g. Spain (Aranese, Andalusian), France (different languages and dialects in all the regions in France) and Italy (Venetian, Roman, Salentino), etc. There is much literature about these languages and their dialects, which we skip here.

Why does all this variety occur and develop everywhere? This question takes us back to the fractals. As we recall, fractals can change their measures, but keep their similarity. They can also be unpredictable and random. We have seen that these features are also common to languages and dialects.

A language begins from a small core; it develops and grows in time and space. Language structure is basically the same for all languages and dialects, since they are based on pronunciation, grammar (morphology and syntax) and vocabulary items. Languages can engender many dialects, which are like the copies of random fractals. The copies (i.e. dialects) of a language are not exactly the same, for each dialect varies to some extent from the next. Dialects may use, for instance, the same structures but certain speech sounds that differ from the core language in certain changeable elements.

Fractals in nature can be infinite; also languages keep evolving all the time like random fractals (infinitely, as far as we can predict). That is why dialects and languages cannot be

\footnotetext{
${ }^{2}$ Received Pronunciation was defined as 'the standard accent of English as spoken in the south of England' although it can be heard from native speakers throughout England and Wales. It can still be heard as used by BBC broadcasters. See [21].
} 
described once and for all: they keep changing all the time. Various features die out while others step onto the stage for a while.

Language changes depend, among others, on external factors such as education, culture, social inter-communal contacts and limitations, financial conditions, etc. Like random fractals, these factors change the linguistic forms even with the tiniest differences of the condition at the outset.

Language, almost the most characteristic human creation, has conditions or rules that seem common to the external, physical world and life. Deeper scrutiny of the structural features of fractal details in relation to languages will reveal additional similar and interesting features between them (in addition to obvious differences). Researches on various aspects of the links between fractals and language already exist and have begun to spread, though they are not mentioned here because they are beyond the goals of this article. However, these are only the beginnings of this study field, and there is much more to do in order to understand linguistic phenomena in terms of fractals.

\section{REFERENCES}

[1] Lesmoir-Gordon, N. (ed.), The Colours of Infinity: The Beauty and Power of Fractals, Springer Verlag: London, 2010.

[2] Self-similar Fractals, available at http://www.fractalcurves.com/Turtle.html

[3] Rosenhouse, G., Colours of noise fractals and applications. International Journal of Design \& Nature and Ecodynamics, 9(4), pp. 255-265, 2014. https://doi.org/10.2495/DNE-V9-N4-255-265

[4] Fractals examples available at http://fractalfoundation.org/OFC/OFC-1-1.html (accessed 8 July 2016)

[5] Fractal example available at https://upload.wikimedia.org/wikipedia/commons/2/21/ Mandel_zoom_00_mandelbrot_set.jpg (accessed 8 July 2016)

[6] Tomasello, M., Origins of Human Communication, MIT Press: Cambridge, MA, 2008.

[7] Kennison, S., Introduction to Language Development, Sage: Los Angeles, CA, 2013.

[8] Hugh, A. \& Trudgill, P., English Accents and Dialects: An Introduction to Social and Regional Varieties of British English, Edward Arnold: London, 1990.

[9] Jespersen, O., Language: Its Nature, Development and Origin, George Allen and Unwin Ltd: London, 1922.

[10] Sapir, E., Language: An Introduction to the Study of Speech, Harcourt, Brace and Co: New York, 1921.

[11] Peterson, G.E. \& Barney, H.L., Control methods used in a study of the vowels. Journal of the Acoustical Society of America (JASA), 24(2), pp. 175-184, 1952. https://doi.org/10.1121/1.1906875

[12] Amir, N., Amir, O. \& Rosenhouse, J., Colloquial Arabic vowels in Israel: A comparative acoustic study of two dialects. Journal of the Acoustical Society of America (JASA), 136(4), pp. 1895-1907, 2014.

[13] Map of the Arabic Dialects of the Levant, From Fuṣhā to 'Āmmiyya, available at https:// learnammiyya.wordpress.com/tag/sociolinguistics/ (accessed 10 July 2016)

[14] Kaye, A.S. \& Rosenhouse, J., Arabic dialects and Maltese, In The Semitic Languages, ed R Hetzron, Routledge Publishing House: London, 263-311, 1997.

[15] Urban Levant Arabic Consonants and Vowels, available at https://en.wikipedia.org/ wiki/Levantine_Arabic_phonology) 
[16] Rosenhouse, J., The Bedouin Arabic Dialects: General Characteristics and a Detailed Study of North Israel Bedouin Dialects, Harrassowitz Verlag: Wiesbaden, 1984.

[17] Geva-Kleinberger, A., Die arabischen Stadtdialekte von Haifa in der ersten Haelfte des 20. Jahrhunderts, Harrassowitz Verlag: Wiesbaden, 2004.

[18] Havelova, A., Arabic dialects of Nazareth: A Dialectological and sociolinguistic description, Ph.D. dissertation, University of Haifa: Haifa, 2000.

[19] Meron, J. \& Kabha, R., Tales of the Wadi, The Institute for Arabic Studies; Givat Haviva, 1993.

[20] Schmidt, H. \& Kahle, P., Volkserzählungen aus Palästina (Vol. 1), Vandenhoeck and Ruprecht: Goettingen, 1918.

[21] Received Pronunciation (RP), available at https://en.wikipedia.org/wiki/Received_Pronunciation (accessed 2 September 2016)

[22] Labov, W., Principles of Linguistic Change; Cognitive and Cultural Factors, Wiley Blackwell: Chichester, 2010.

[23] Trudgil, P., Dialects in Contact, Basil Blackwell: Oxford, 1986.

[24] Rosenhouse, J. "Vocabulary changes in an Eastern Arabic dialect region in the 20th century," Casini, L., La Spisa, L. and Suriano, A.R. (eds.) In Quaderni di Studi Arabi N.S. 9, The Languages of Arabic LiteratureUn Omaggio a Lidia Bettini, eds. L Casini, L, La Spisa, \& A.R Suriano, pp. 99-114, 2014. 